\title{
Increase of Ecological Safety of Solid Fuel Combustion
}

\author{
Tatyana A. Kulagina* and Maxim E. Grishchenko \\ Siberian Federal University \\ 79 Svobodny, Krasnoyarsk, 660041, Russia
}

Received 12.01.2015, received in revised form 14.02.2015, accepted 23.04.2015

\begin{abstract}
In the article on the basis of a comprehensive study of solid waste combustion processes formulate recommendations for the reconstruction of a typical production equipment to improve the the efficiency of of the combustion process in order to reduce pressures on the environment by the example of CJSC "Polyus". The most important challenge in this regard is development of intensive energy saving. Presents the results $X$-ray diffraction and thermal analysis synchronous.
\end{abstract}

Keywords: energy efficiency, waste combustion processes, carbon black, carbon monoxide, polycyclic aromatic hydrocarbons.

\section{Повышение экологической безопасности сжигания твердого топлива}

\section{Т.А. Кулагина, М.Е. Грищенко}

Сибирский федеральный университет Россия, 660041, Красноярск, пр. Свободный, 79

В статье на базе комплексного исследования твердых отходов прочессов горения сформулированы рекомендации по реконструкции типового технологического оборудования для повышения эффективности процесса горения с иелью снижения нагрузки на окружающую среду на примере $3 A O$ «Полюс». Наиболее важной проблемой в этой области является развитие интенсивного энергоресурсосбережения. Представлены результаты рентгеноструктурного и синхронного термического анализа.

Ключевые слова: энергоэффективность, отходы процессов горения, сажа, углерода оксид, полициклические ароматические углеводороды.

Обеспечение принципа энергоэффективности - одно из важнейших условий функционирования и дальнейшего развития современной промышленности. Наиболее важной проблемой в этой области является развитие интенсивного энергоресурсосбережения, поскольку потенци-

(C) Siberian Federal University. All rights reserved

* Corresponding author E-mail address: tak.sfu@gmail.com 
ал экстенсивных методов в значительной мере исчерпан. На практике существуют два альтернативных пути ресурсной и, что не менее важно, экологической эффективности жизнедеятельности:

- реконструкция существующих технологических процессов на принципах построения малоотходных производств и безотходных комплексов;

- интенсификация производства полезного продукта при одновременном снижении потребления энергетических и материальных ресурсов в результате использования новых наукоемких технологий.

Типичная ситуация для современных энергетических предприятий с очень низкими эксергетическими показателями, в частности, из-за большого недожога, образующегося, как правило, при сжигании твердого топлива. Продукты незавершенного горения, такие как сажа, углерода оксид, полициклические ароматические углеводороды (ПАУ), относятся к канцерогенным веществам $[1,2]$.

При сжигании углеводородных топлив в топках котлов и печей наряду с процессами окисления происходит их пиролиз. Экспериментальные исследования термического разложения углеводородных топлив показывают их радиально-цепной механизм, инициируемый мономолекулярным разложением исходного углеводорода.

Благоприятные условия образования ПАУ в продуктах сгорания возникают в топках котлов небольшого объема и с высокой степенью экранирования, что характерно для малых энергетических объектов. Определяющим в конечном выходе ПАУ является режим сжигания топлива, т.е. количество окислителя и качество смесеобразования, температурные параметры и время пребывания газов в высокотемпературной зоне. Так, с целью определения качества сжигания топлива на котле № 5 ЗАО «Полюс» были отобраны пробы угля и золы в бункере золоуловителя (на рис. условно названо «золоотвал») и пробы золы после золоуловителя (циклона). С целью определения горючей части в пробах проведены рентгеноструктурный и синхронный термический анализ (прибор STA 449 F1 Jupiter). На рис. 1-3 представлены дифрактограммы образцов (прибор дифрактометр D8 ADVANCE).

Рентгенофазный анализ угля свидетельствует о том, что уголь состоит преимущественно из рентгеноаморфной фазы. Кристаллические фазы присутствуют в незначительных количествах и представлены в основном кварцем $\mathrm{SiO}_{2}(d=3,35 \AA)$, каолинитом $(d=4,15 ; 3,56 \AA)$, гипсом-полугидратом $(d=6,03 ; 3,00 ; 1,84 \AA)$, гематитом $(d=2,70 ; 2,55 \AA)$, возможно кальцитом $\mathrm{CaCO}_{3}$. Идентификация кристаллической составляющей затруднена в связи с тем, что линии кристаллических фаз маскируются широким «галообразным» максимумом, характерным для углей. Дифрактограмма пробы золоотвала характеризуется более размытым, широким максимумом, на фоне которого четко просматриваются пики, характерные для кварца $\mathrm{SiO}_{2}$, ангидрита $\mathrm{CaSO}_{4}$, гематита $\mathrm{Fe}_{2} \mathrm{O}_{3}$, полевых шпатов. Дифрактограмма твердых выбросов в атмосферу после сжигания угля схожа с дифрактограммой золоотвала.

Минеральную часть выделяли озолением проб угля, золоотвала и твердых выбросов при $1000{ }^{\circ} \mathrm{C}$. В процессе сжигания угля (озоления) образуются вторичные минералы в результате процессов дегидратации, декарбонизации и взаимодействия компонентов минеральной части между собой и газообразными продуктами горения. Дифрактограммы минеральной части вышеуказанных проб приведены на рис. 4-6. 


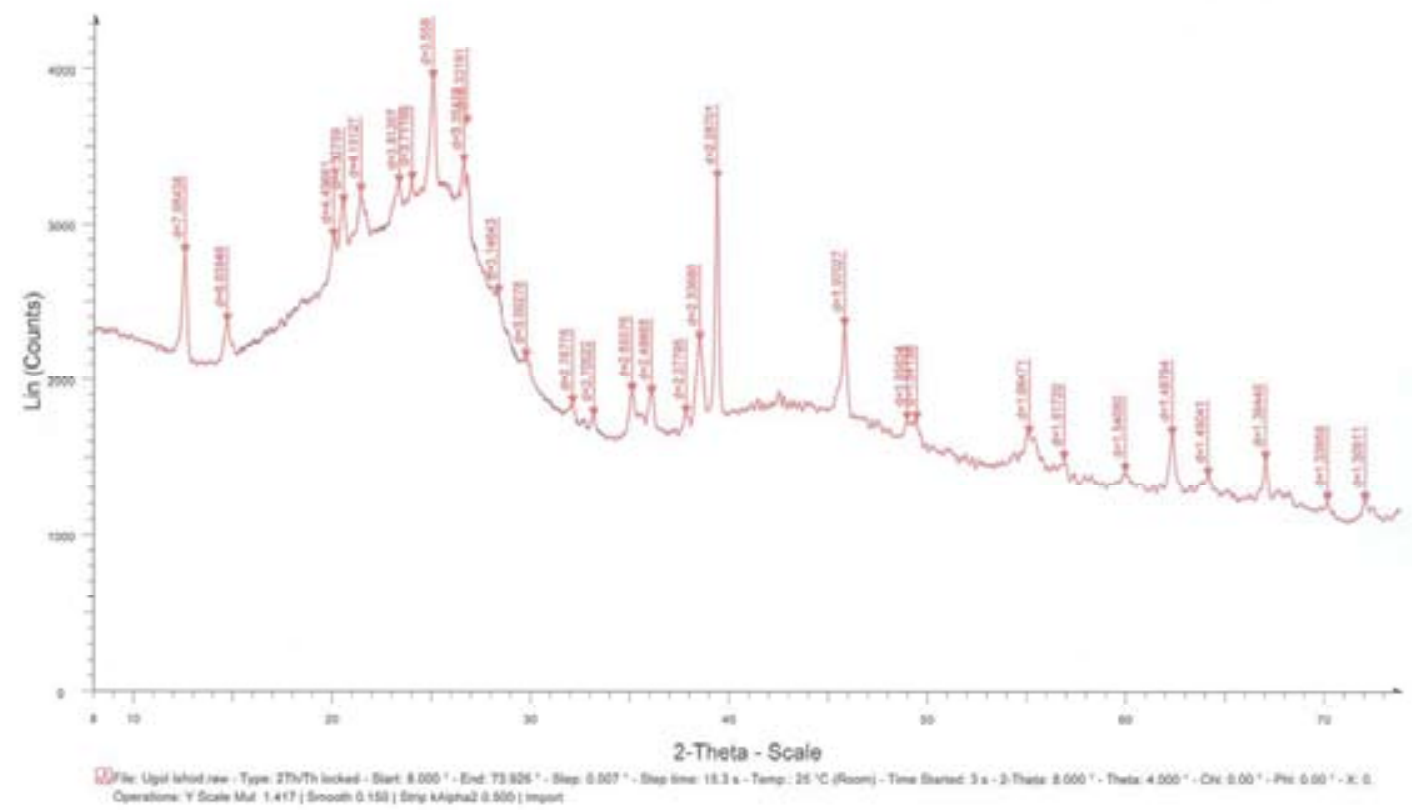

Рис. 1

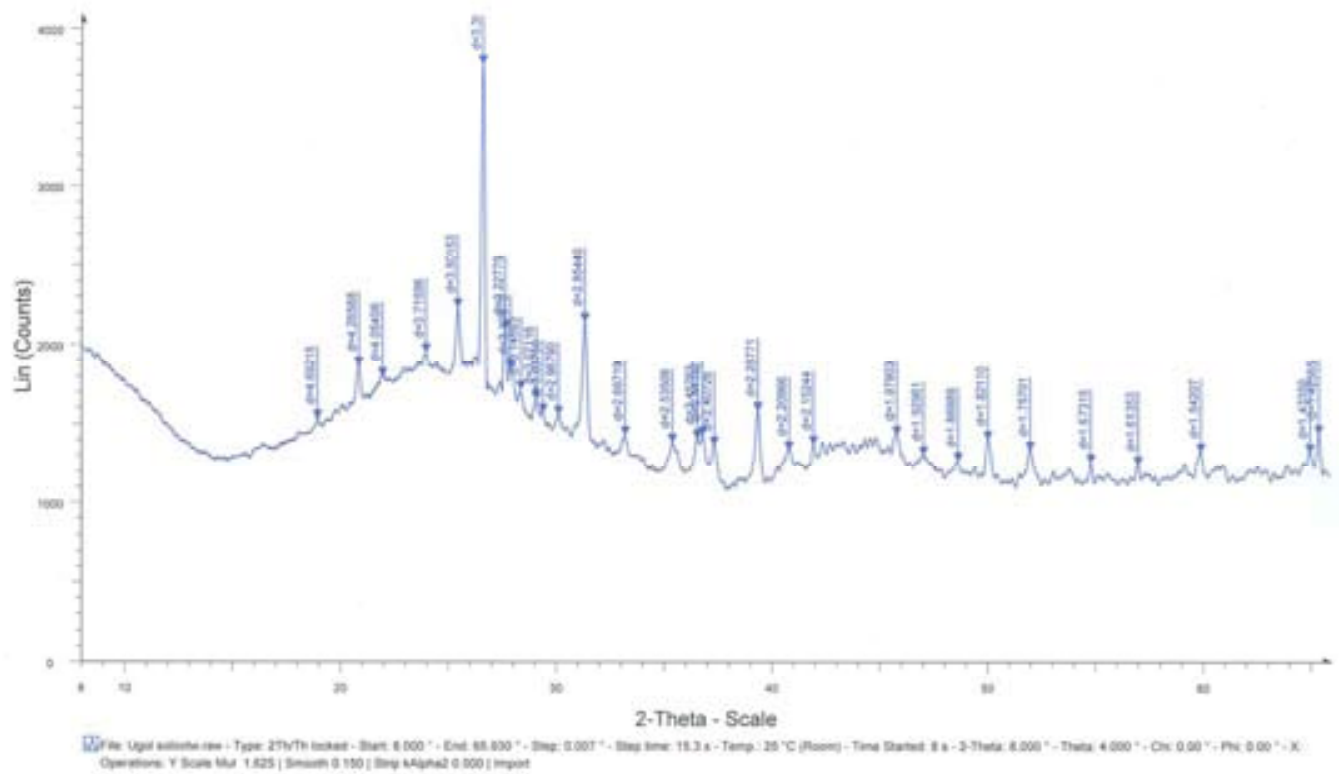

Рис. 2 


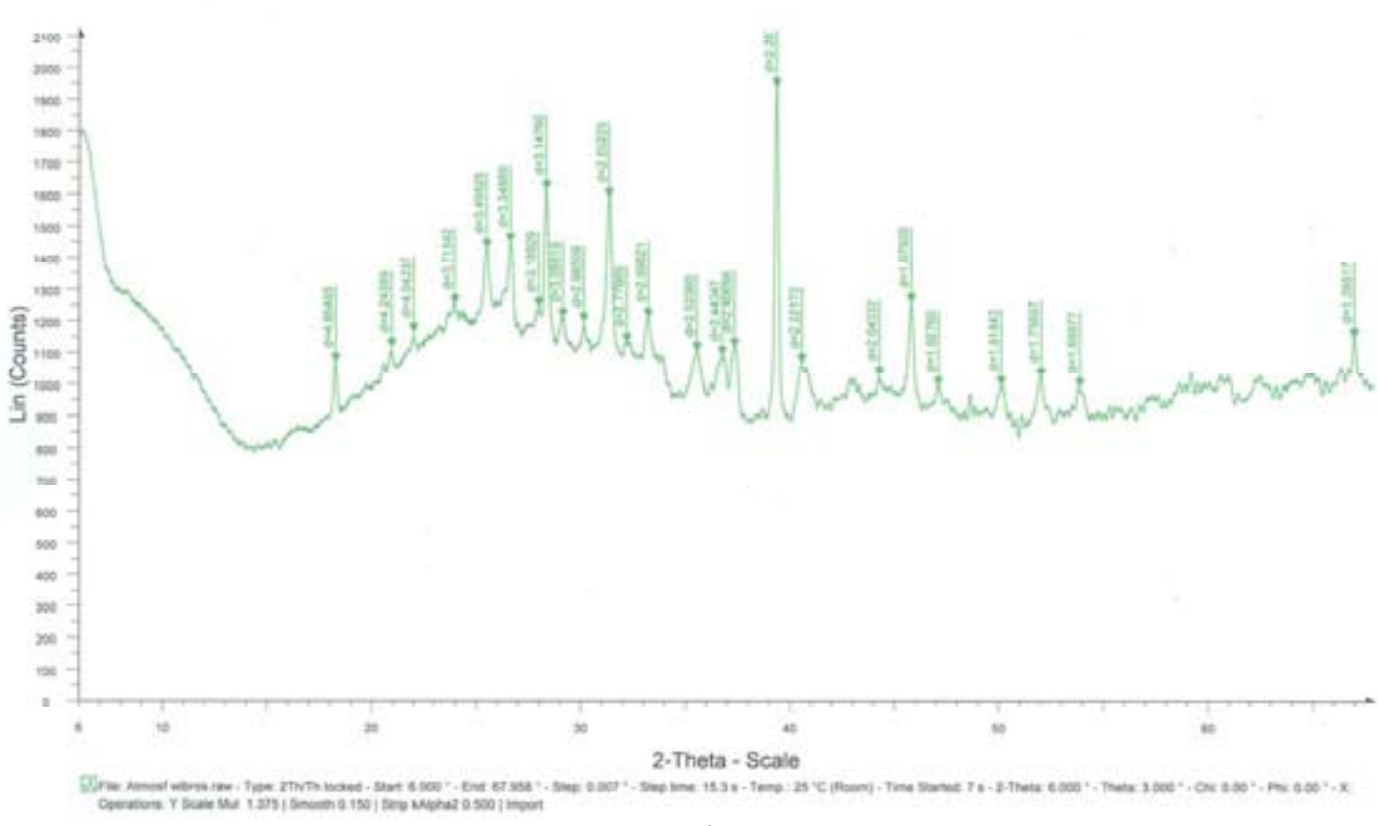

Рис. 3

Таблица 1. Химический состав (мас \%)

\begin{tabular}{|c|c|c|c|}
\hline Наименование & $\begin{array}{c}\text { Уголь, минеральная } \\
\text { часть }\end{array}$ & $\begin{array}{c}\text { Золоотвал, минеральная } \\
\text { часть }\end{array}$ & $\begin{array}{c}\text { Атмосферные выбросы, } \\
\text { минеральная часть }\end{array}$ \\
\hline $\mathrm{SiO}_{2}$ & 32,4 & 36,82 & 38,30 \\
\hline $\mathrm{CaO}$ & 16,95 & 18,42 & 18,98 \\
\hline $\mathrm{Al}_{2} \mathrm{O}_{3}$ & 25,87 & 25,39 & 24,67 \\
\hline $\mathrm{Fe}_{2} \mathrm{O}_{3}$ & 10,89 & 10,0 & 2,76 \\
\hline $\mathrm{MgO}$ & 3,40 & 2,18 & 4,99 \\
\hline $\mathrm{SO}_{3}$ & 8,92 & 5,97 & 0,38 \\
\hline $\mathrm{Na}_{2} \mathrm{O}$ & 0,41 & 0,34 & 0,635 \\
\hline $\mathrm{K}_{2} \mathrm{O}$ & 0,52 & 0,43 & \\
\hline
\end{tabular}

Основными фазами указанных проб являются кварц $\mathrm{SiO}_{2}$, ангидрит $\mathrm{CaSO}_{4}$, гематит $\mathrm{Fe}_{2} \mathrm{O}_{3}$, геленит $2 \mathrm{CaO} \mathrm{Al} \mathrm{O}_{3} \mathrm{SiO}_{2}$, полевые шпаты, муллит $3 \mathrm{Al}_{2} \mathrm{O}_{3} 2 \mathrm{SiO}_{2}$, возможно присутствие СаO. Дифрактограммы минеральной части проб угля, золоотвала, твердых выбросов схожи между собой. Химический состав минеральной части проб определен волновыми рентгенофлуоресцентным методом на приборе ARL OPTIM X (фирма Thermo Scientific, Швейцария). Результаты анализа приведены в табл. 1.

Проанализировав результаты экспериментальных исследований, следует отметить, что в пробах золы после золоуловителя и самом бункере золоуловителя присутствует именно углерод топлива. Для уточнения полученных результатов были получены термограммы образцов, представленные на рис. 7-9, которые свидетельствуют о большой потере массы образцов. Так 


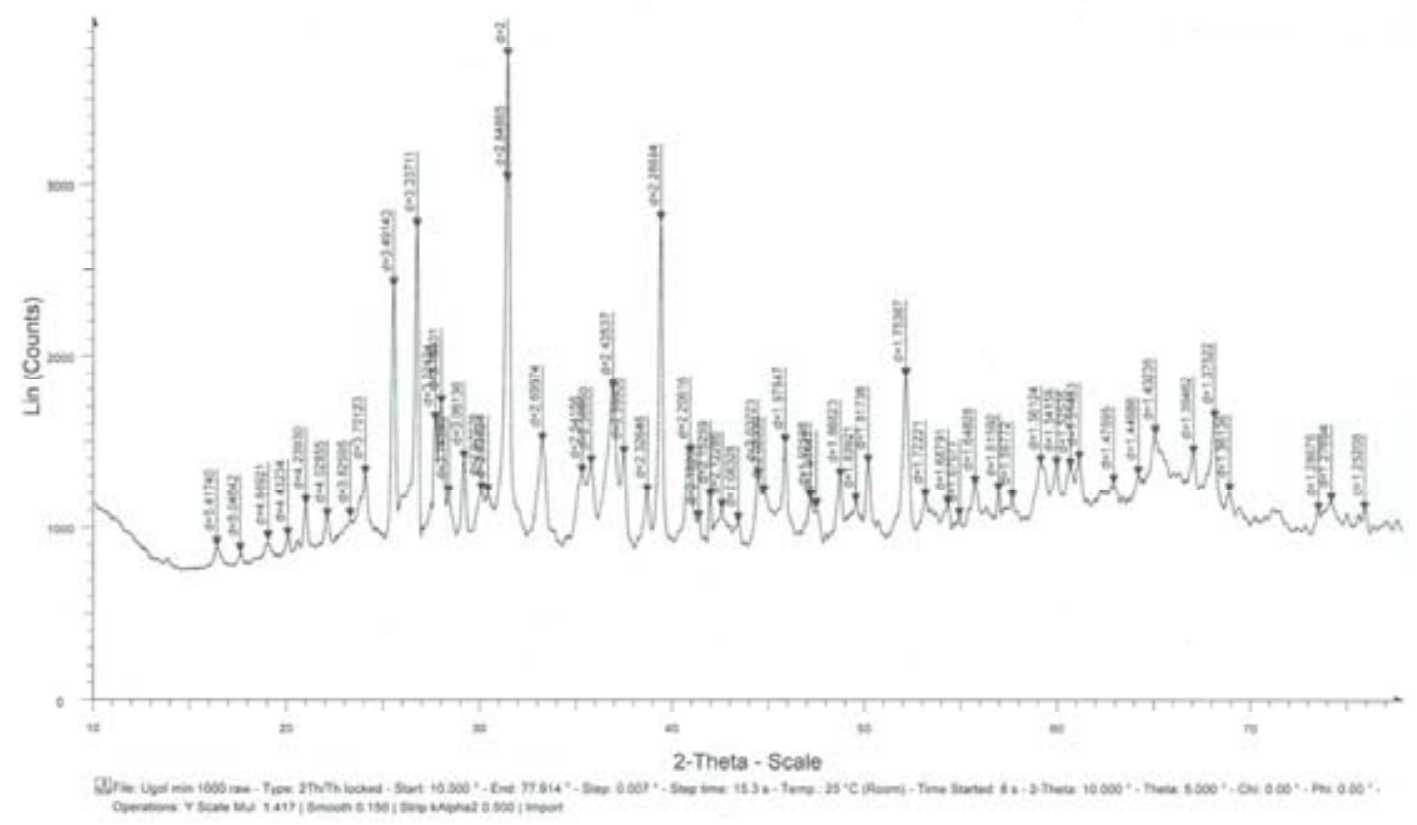

Рис. 4

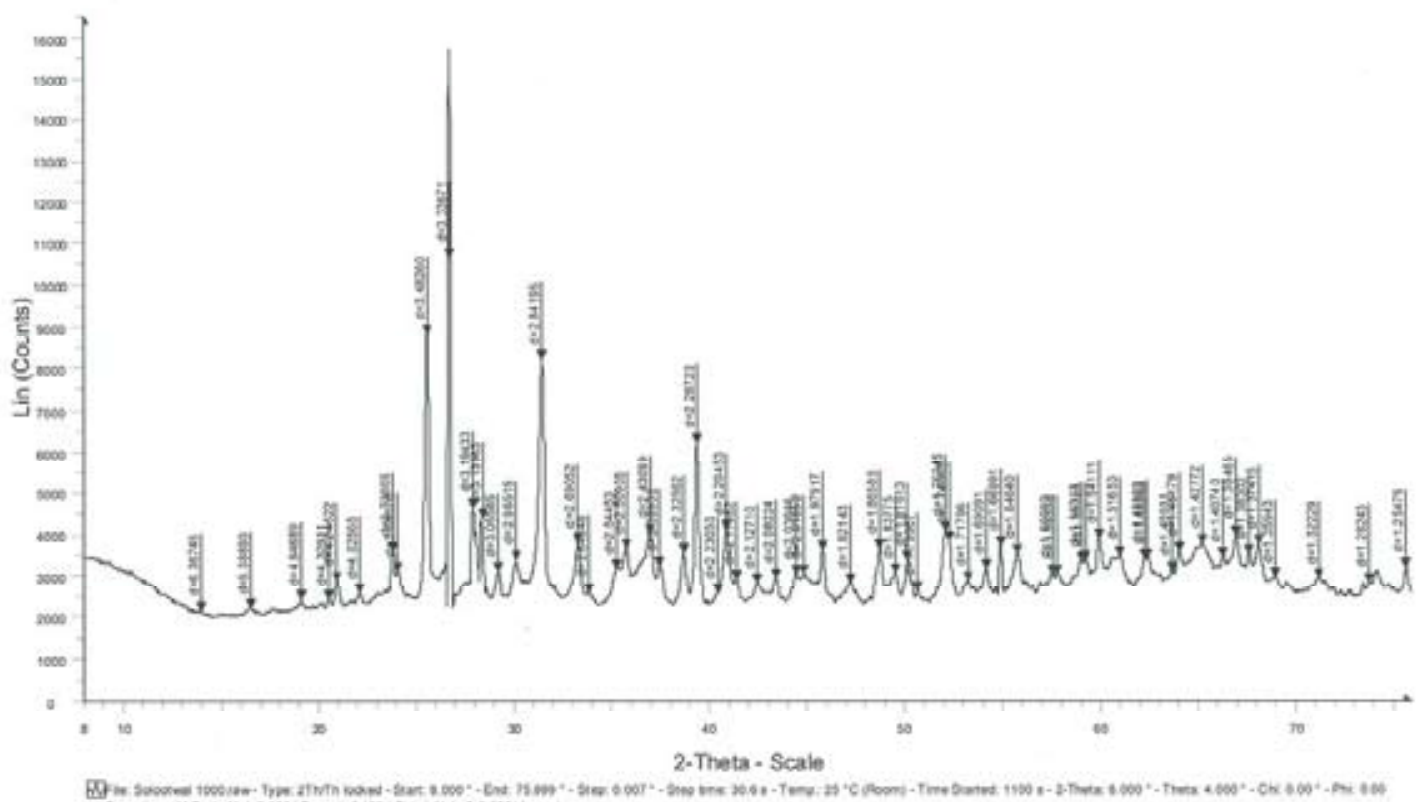

Рис. 5 


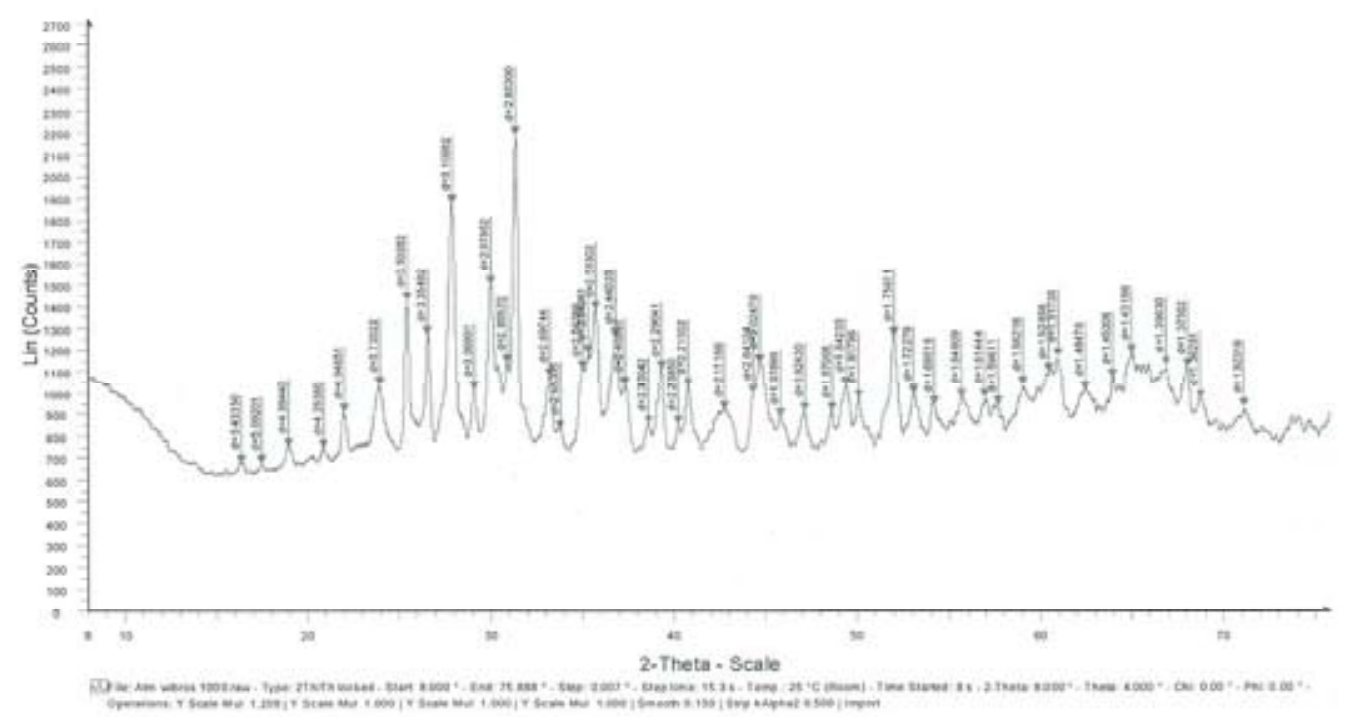

Рис. 6

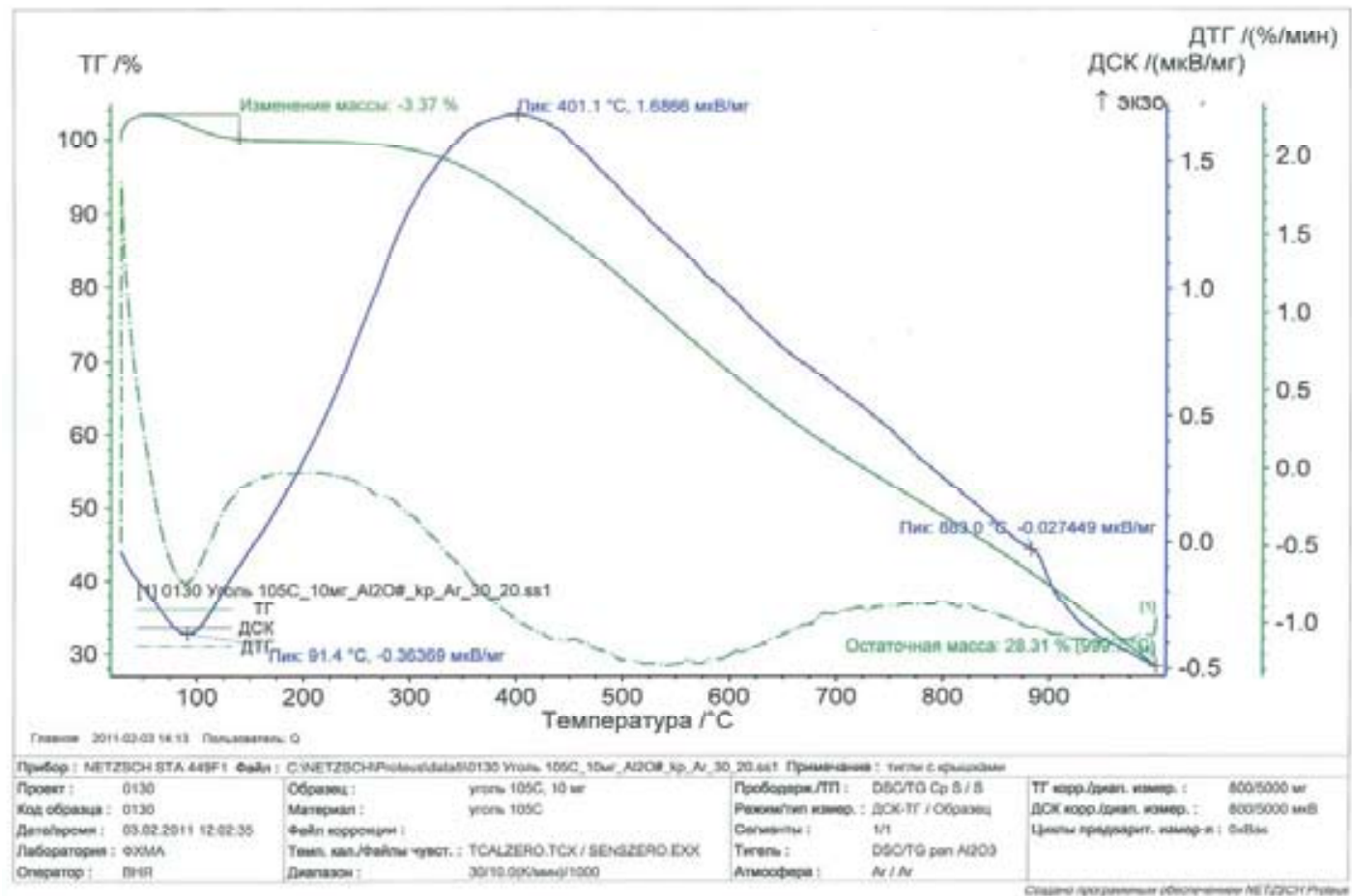

Рис. 7 


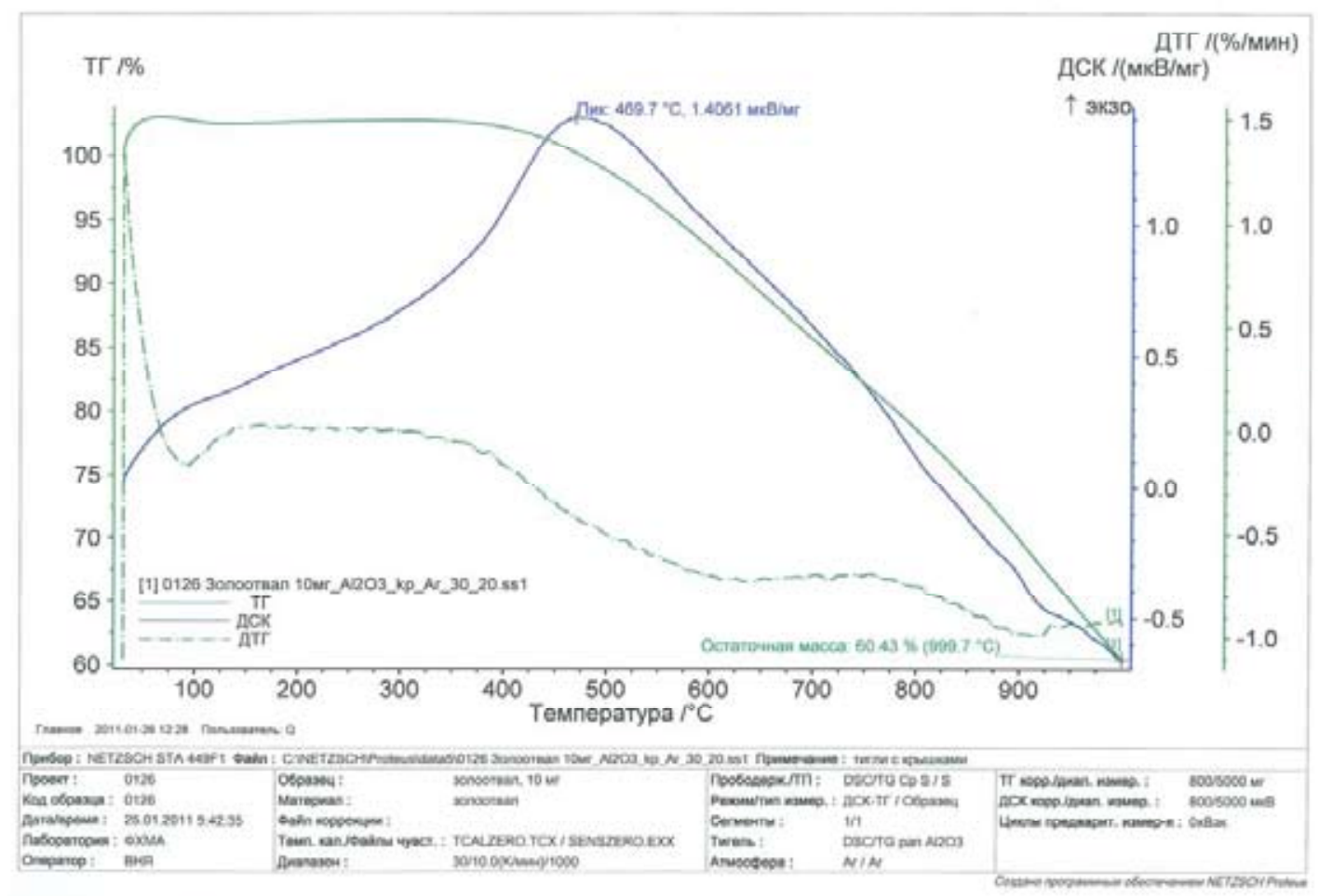

Рис. 8

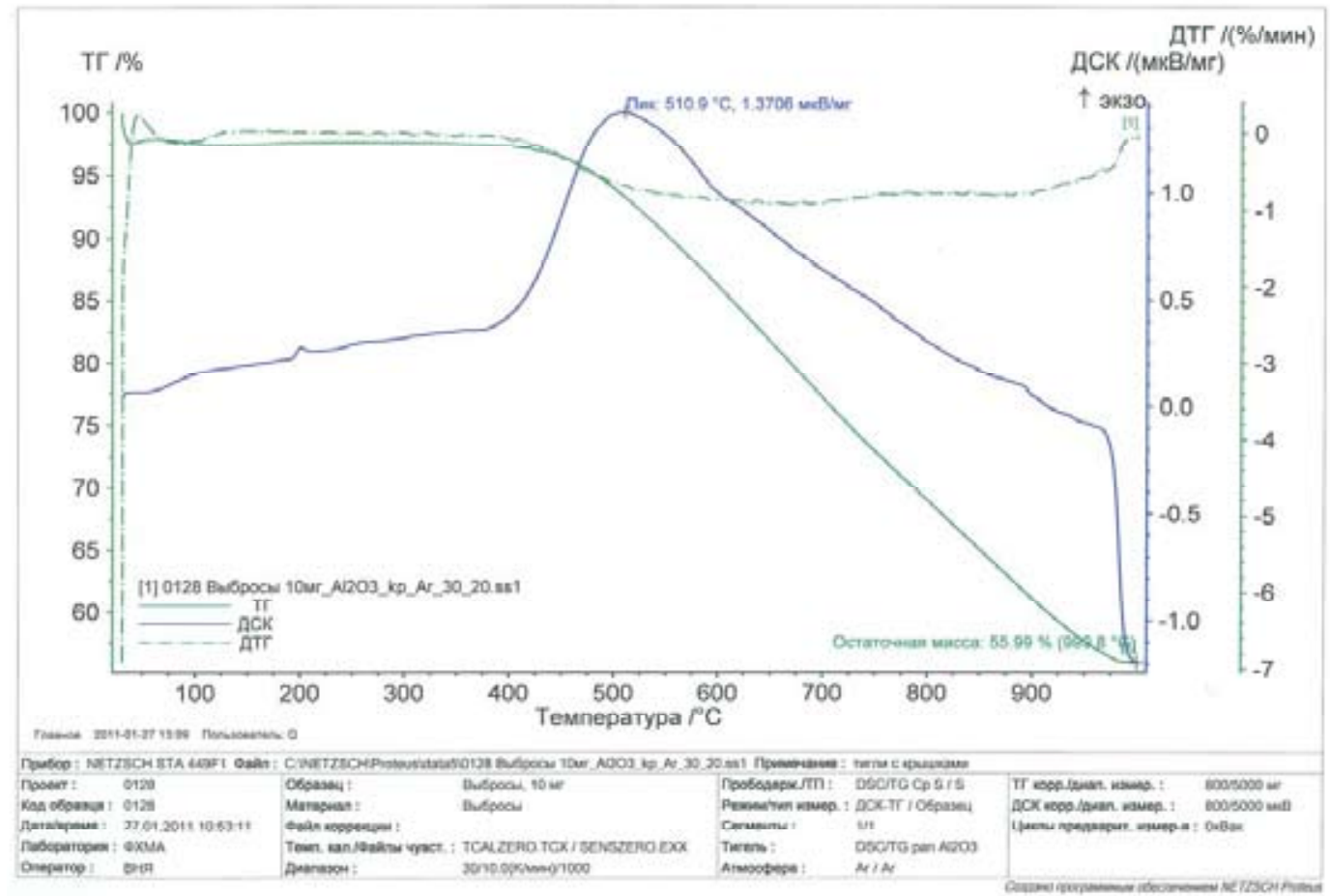

Рис. 9 
на пробе золы после золоуловителя (выброс в атмосферу) остаточная масса составляет 55,99 \%, значит, углерод топлива в исследуемой пробе составляет 54,01 \%. Теоретически его не должно быть совсем.

Полученные результаты исследования позволяют предположить, что при использовании типового технологического оборудования не всегда удается обеспечить высокую эффективность процесса горения. Процессы, протекающие в топке, многообразны, тесно взаимосвязаны, что затрудняет их анализ. Основными топочными процессами являются горение и теплообмен. Вместе с тем аэродинамика топки определяет устойчивость и экономичность этих процессов.

\section{Выводы}

В топочном объеме происходят сложные физико-химические изменения составляющих топлива. Свойства и состав конечных продуктов превращения топлива зависят не только от его вида, но и от условий организации топочного процесса (температуры, состава среды, аэродинамических условий, параметров топочного пространства).

Анализ исследований позволяет сделать следующее заключение: для повышения качества сжигания топлива в исследуемом котле необходимо запланировать реконструкцию топки, например, рекомендовать перевести процесс сжигания в кипящий слой, так как образование и рост сажистых частиц зависят прежде всего от наличия достаточного количества окислителя в зоне горения, а также от способа и качества смешения топлива с окислителем (воздухом). В результате будет наблюдаться снижение эмиссии загрязняющих веществ, уменьшится негативное воздействие на окружающую среду и гарантируется экономия углеводородного топлива.

\section{Список литературы}

[1] Кулагина Т.А., Кузьменко Т.Н., Грищенко М.Е. // Журнал СФУ. Техника и технологии. 2013 (6). № 5. 591-604.

[2] Кулагина Т.А., Грищенко М.Е., Кузьменко Т.Н. // Инженерно-экологические проблемы энергосбережения в строительстве и ЖКХ: сборник научных трудов № 2 / ред. Н.А. Цветков. Томск : Изд-во Том. гос. архит.-строит. ун-та, 2013. С. 110-111. 